\title{
LITERATURA BRASILEIRA E DISJUNÇÃO: CEGUEIRA SOCIAL EM "EVOLUÇÃO", DE MACHADO DE ASSIS
}

\section{LUÍS BUENO}

Universidade Federal do Paraná Curitiba, Paraná, Brasil

Resumo: Este trabalho apresenta uma proposta geral de abordagem da história literária brasileira centrada na ideia de disjunção e procura demonstrar sua validade por meio da leitura de um conto de Machado de Assis, "Evolução".

Palavras-chave: História da literatura brasileira; Conto; "Evolução".

\section{BRAZILIAN LITERATURE AND DISJUNCTION: SOCIAL BLINDNESS IN MACHADO DE ASSIS'S "EVOLUÇÃO"}

Abstract: This paper introduces a general proposal for approaching the history of Brazilian Literature based on the concept of disjunction, and seeks to show the proposal's validity by analyzing "Evolução," a short story by Machado de Assis.

Keywords: Brazilian literary history; Short story; "Evolução".

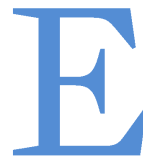

m 2017, Chico Buarque lançou uma canção, "As caravanas", que faz um pequeno mas abrangente retrato do Brasil. Trata-se de uma narrativa em que as praias da zona sul do Rio são invadidas por caravanas compostas de "estranhos / Suburbanos tipo muçulmanos" (BUARQUE, 2017, p. 20), ou seja, moradores do próprio Rio de Janeiro vindos de localidades como Arará, Caxangá, Chatuba, Irajá, Penha e Maré. Num primeiro momento, em procedimento irônico, o eu-lírico se posiciona como um morador da zona sul sentindo que um espaço legitimamente seu é de fato invadido. Esse movimento se sustém por quatro estrofes, atingindo seu auge na última delas, que diz o seguinte: 
Com negros torsos nus deixam em polvorosa

A gente ordeira e virtuosa que apela

Pra polícia despachar de volta

O populacho pra favela

Ou pra Benguela, ou pra Guiné. (BUARQUE, 2017, p. 20)

O desejo que ela expressa é radical: o de que os estranhos sejam tocados de volta para casa pelas autoridades. Um movimento no espaço, é claro, mas também no tempo, se possível. É o desejo de que a história do Brasil volte sobre seus próprios passos para um tempo em que era possível criar um país sem esses estranhos, que permaneceriam em seus lugares de origem na África.

Nas duas estrofes finais, a primeira das quais cantada numa segunda parte da melodia, o que amplia o efeito, a voz lírica muda de tom, e uma confusão de pontos de vista se estabelece, já que a sensação de invasão se agudiza ainda mais, chegando ao desejo do extermínio e, num movimento imprevisto, se mistura a uma voz que diz o quanto é absurdo sentir-se invadido dessa forma:

\author{
Sol, a culpa deve ser do sol \\ Que bate na moleira, o sol \\ Que estoura as veias, o suor \\ Que embaça os olhos e a razão \\ E essa zoeira dentro da prisão \\ Crioulos empilhados no porão \\ De caravelas no alto mar
}

"Tem que bater, tem que matar" engrossa a gritaria

Filha do medo, a raiva é mãe da covardia

Ou doido sou eu que escuto vozes

Não há gente tão insana

Nem caravana do Arará. (BUARQUE, 2017, p. 20-21)

O que a canção de Chico Buarque expressa de modo exemplar e novo é um dos problemas básicos da vida brasileira: a fragmentação de nossa sociedade, impulsionada pelas desigualdades gritantes que a marcam. Brasileiros vendo brasileiros como estrangeiros, cariocas vendo cariocas como invasores. É uma situação insolúvel, que reproduz nas prisões os navios negreiros (em mais um curto-circuito temporal que dá profundidade 
ao que se diz) e que aparentemente só pode ser superada com a negação de que tal divisão exista. Doideira, portanto.

A tradição da história da literatura brasileira concentrou seus esforços, segundo o que se diz desde os primeiros esboços críticos e historiográficos, surgidos após a Independência, na ideia de que por aqui a literatura foi o espaço para forjar uma unidade nacional difícil de ver na vida social, como se a literatura procurasse inventar um Brasil antes que ele existisse. Ressalte-se que tal atitude não constituiu algum tipo de doideira local, especificamente nossa. Afinal, os alemães, que criaram as bases da moderna história literária nacional, também andaram à procura de uma unidade num espaço fragmentado, inventando uma Alemanha antes que ela existisse historicamente.

A importância de um livro como Formação da literatura brasileira talvez resida justamente na descrição desse processo, o do desejo dos brasileiros, ou de alguns brasileiros, de ter uma literatura - e também uma nação. "O leitor perceberá que me coloquei deliberadamente no ângulo dos nossos primeiros românticos", diz Antonio Candido (1981, p. 25) no final do primeiro capítulo do livro, ou seja, na perspectiva de quem viveu intensamente a doideira da criação de uma literatura nacional num país dividido.

Dá especial significação ao livro, mais do que isso, o fato de ter sido escrito numa outra fase dessa doideira. O livro de Antonio Candido, como se sabe, foi concebido quando um conceito fundamental, exatamente o de "formação", estava maduro, depois de ter sido desenvolvido por intelectuais como Gilberto Freyre, Caio Prado Júnior, Sérgio Buarque de Holanda, entre outros. As diferenças entre os primeiros românticos e essa geração de intérpretes do Brasil é imensa, mas em ambas podemos localizar um traço interpretativo comum, expresso na ideia de que ainda não estávamos formados. O ambiente nacional disruptivo é visto como matéria-prima a ser moldada para a criação de uma nação e de uma literatura pelos românticos; e como realidade a ser superada para que o país possa se formar, ou seja, atingir o momento em que essa disruptividade cesse e uma sociedade justa e democrática se crie, para os "formativos". É difícil dizer se são duas utopias diferentes ou a mesma utopia desenvolvida em ambientes ideológicos distintos. De um modo ou de outro, o Brasil formado, completo, estaria sempre no futuro.

Olhando de hoje, essa utopia (ou essas utopias) não parece encontrar mais ambiente ideológico que lhe dê rendimento. Os impasses não foram 
superados e o país continua dividido, se é que não está mais dividido ainda que na primeira metade do século XX. Ora, isso não invalida o rendimento que essa tradição já teve, antes pede a criação de uma outra perspectiva. Não é coincidência que a Formação da literatura brasileira seja a última grande obra de uma linhagem. Afinal, suas conclusões conduzem a um paradoxo: o de que, a despeito de o Brasil eventualmente não estar formado, sua literatura já está. Paradoxo para a tradição formativa, é evidente, não para o pensamento sobre o Brasil ou sobre a literatura brasileira. É plenamente possível, aliás, ver esse paradoxo como o ponto em que um conceito rentável chega a seu limite, escancarando a necessidade de pensar em outros termos para seguir adiante.

É este o ponto de partida para a ideia que gostaria de propor aqui, a de disjunção. A hipótese de trabalho, por um lado, é a de que a sociedade brasileira já está plenamente formada há muito tempo, assim como um sistema literário brasileiro já está formado há muito tempo. Só que não se trata de uma sociedade orgânica como a melhor parcela da intelectualidade brasileira deseja, mas sim de uma sociedade disjuntiva. A disjunção é, nessa perspectiva, elemento característico da literatura e da vida nacionais - sem prejuízo de o ser também de outras sociedades modernas atravessadas pela desigualdade. Libertando-nos desse futuro que estava sempre no horizonte dos intelectuais "formativos", um futuro que nunca vem, nos concentraremos apenas no presente e no passado e admitiremos que a modernidade se instalou profundamente entre nós porque a disjunção não é incompatível com essa mesma modernidade, antes está prevista por ela e de fato é seu ponto de fuga.

No que diz respeito à literatura brasileira, a hipótese é a de que, independentemente da permanência da utopia de um país uno, há uma tradição disjuntiva na literatura brasileira. Segundo essa hipótese, é até possível escrever uma história não totalizadora da literatura brasileira organizada em torno da ideia de disjunção. A expectativa (sempre somos otimistas na fase das hipóteses) é criar uma maneira de ver a tradição literária brasileira que fique menos obcecada com nosso descompasso frente à literatura dos países centrais, ainda que sem desprezar a presença intelectual dessas literaturas, na medida em que se estabelece um elemento claro de análise que permite ver certas demandas específicas de fazer literatura no Brasil.

O resultado talvez venha a ser uma visão de conjunto de uma literatura bastante consciente de suas limitações e de seu potencial, que temperou, na 
prática do fazer estético, a utopia de um Brasil a construir, ou seja, lidou lucidamente com o problema que é tratar do tempo presente e suas limitações.

A canção de Chico Buarque antes citada, por exemplo, poderia integrar essa história. Afinal, a disjunção brasileira é sua matéria básica. Tematicamente isso fica muito claro, é mesmo seu assunto. Em termos de forma, as coisas ficam sempre um pouco menos evidentes, mas nas rápidas observações feitas já se indica que é uma confusão de pontos de vista que dá à letra seu sentido, no contraste entre o que o eu-lírico incorpora como visão nas primeiras quatro estrofes e nas duas finais. A disjunção que a canção desenha, portanto, não é apenas a que separa "a gente insana" da zona sul das caravanas de "estranhos" invasores, mas também a que divide "a gente insana" da zona sul e aqueles que os consideram insanos e que creem não estar ouvindo vozes, representados pelo eu que se apresenta de maneira inequívoca apenas no antepenúltimo verso, com aquele claríssimo "sou eu". São pertencimentos diferentes à sociedade brasileira, os primeiros excluindo e os outros incluindo os estranhos. A ambiguidade daquele "com negros torsos nus deixam em polvorosa" que, quando ouvido, pode muito bem ser entendido como "com negros torsos nos deixam em polvorosa", dá mais uma volta nesse jogo de pertencimentos, ao sugerir, ao final da audição, que o eulírico, mesmo que enxergue para si um outro pertencimento, mais abrangente, sabe que não pode negar sua ligação com a mesma "gente insana" de quem se sente tão distante. São seus vizinhos de zona sul, sua gente.

Para tentar deixar mais claro o que se quer dizer, passemos à análise literária propriamente dita, que sempre deixa tudo mais claro. Não sem antes fazer duas advertências. A primeira é: o problema que aqui se coloca fica mais visível em obras usualmente tidas como formalmente problemáticas ou disjuntivas quando confrontadas com as matrizes literárias europeias de que derivariam. É o caso, por exemplo, do romance $A$ carne, de Júlio Ribeiro, tido como falho pela crítica, pois estaria dividido de maneira inconciliável entre dois planos narrativos, um tido como verdadeiro, natural e naturalista, o dos amores de Lenita e Barbosa, e um outro, artificialmente introduzido, o do escravo Joaquim Cambinda, que deveria ser descartado para bem da coerência estrutural do romance e de sua localização no cânone naturalista. Décadas de esforço crítico, de José Veríssimo a Manuel Bandeira, apontaram esse como o problema central de fatura do romance. Em nossa leitura, a coerência do projeto do romance se deve justamente à relação entre esses dois planos, que apenas aparentemente estão separados. 
A segunda advertência é: não se trata de apontar obras que simplesmente tematizem as desigualdades no Brasil, ou as mencionem, mas sim propor a ideia de que a ficção brasileira foi formalmente afetada por algo que se pode chamar de disjunção. Assim, por exemplo, não se quer dizer que um romance como $A$ moreninha seja disjuntivo, embora a sociedade brasileira, escravocrata, que se pode ali entrever, seja claramente disjuntiva. Vejamos o que acontece no capítulo 19 do livro, "Entremos nos corações". Depois de um final de semana intenso na Ilha de..., Augusto está de volta à sua rotina de estudante de medicina. Não é fácil, no entanto, voltar à vida normal depois da experiência amorosa que ele tivera no final de semana anterior, quando conhecera Carolina, a Moreninha. Tudo o que lhe interessa é a chegada do final de semana seguinte, quando o que realmente importa para ele poderá ser retomado:

O nosso Augusto, por exemplo, está agora bronco para as lições e impertinente com tudo. Rafael é quem paga o pato: se o inocente moleque lhe apronta o chá muito cedo, apanha meia dúzia de bolos, porque quer ir vadiar pelas ruas; se no dia seguinte se demora só dez minutos, leva dois pescoções, para andar mais ligeiro. Não há, enfim, coisa alguma que possa contentar o sr. Augusto; está aborrecido da medicina, tem feito duas gazetas na aula; de ministerial, que era, passou-se para a oposição; não quer ser mais assinante de periódicos, não há para seus olhos lugar nenhum bonito no mundo; aborrece a corte, detesta a roça e só gosta das ilhas. (MACEDO, 1972, p. 127)

O primeiro que sofre com o sofrimento amoroso de Augusto é o escravo, evidentemente. Leva meia dúzia de bolos ou dois pescoções por dá cá aquela palha. O registro, no entanto, é leve. As pancadas têm graça, a mesma que tem mudar de opinião na política, deixar de assinar periódicos e só gostar das ilhas, porque é numa delas que ficou a amada.

Que a coisa não é leve, no entanto, o próprio romance dá conta de testemunhar no capítulo seguinte. Finalmente chega o domingo e o bordado das moças entra em questão, de forma que Augusto se propõe a aprender a fazê-lo:

- Querem ver, acudiu Felipe, que minha maninha reduz Augusto a aprender a marcar?

- Nada, respondeu a menina; sou muito raivosa e à primeira linha que ele rebentasse, eu o chamaria a bolos. 
- Se é uma condição que me oferece, eu a aceito, minha senhora; ensineme com palmatória.

- Veja o que diz!...

- Repito-o.

- Pois bem, palmatória não, porque, enfim, podia doer-lhe muito; mas, de cada vez que eu julgar necessário, dar-lhe-ei um puxão de orelha. (MACEDO, 1972, p. 136)

Os bolos vão doer demais em Augusto, mas são coisa de menor monta, causa até de riso, quando aplicados a Rafael. Lógico, o ponto de vista é o de quem os aplica, não o de quem os recebe. A insensibilidade, partilhada por narrador, personagens e possível leitor, alimentada pela condição escravocrata, é marca significativa da disjunção brasileira que é episodicamente carreada para a obra, mas não compõe sua estrutura. Está também presente, mais ou menos nos mesmos termos, em $O$ filho do pescador, publicado um ano antes. Em outras palavras: a disjunção não é tratada com consciência, é uma espécie de reflexo condicionado numa sociedade escravocrata, ou seja, a disjunção aí é inoperante do ponto de vista artístico, servindo mais como testemunho de um modo de ver a própria escravidão, que é a forma mais aguda de disjunção no interior de uma sociedade moderna.

Feitas as duas advertências, vejamos o que se busca com a ideia de disjunção, por meio da análise de um texto que nem a tematiza diretamente nem é apontado pela crítica como falho. Trata-se de "Evolução", conto de Machado de Assis que integrou o volume Relíquias de casa velha, de 1906, mas havia sido publicado na Gazeta de Notícias quase vinte anos antes, em 24 de junho de 1884 - antes da Abolição, portanto.

O entrecho do conto é bastante simples. O narrador, Inácio, conta que conheceu Benedito numa viagem de trem, durante a qual se distraíram palestrando. No meio da conversa, Inácio formula a seguinte frase: "Eu comparo o Brasil a uma criança que está engatinhando; só começará a andar quando tiver muitas estradas de ferro" (ASSIS, 1992, p. 704). A partir daí, o conto se desenvolve em torno da maneira como Benedito se apropria dessa frase. Na primeira vez em que se reencontram, Benedito cita-a, acrescentando "é justamente o que o senhor dizia". Na segunda, o que se acrescenta é um "nós dizíamos". Na terceira, a frase integra o discurso de posse de Benedito, eleito deputado, no Parlamento, mas assim caracterizada: "dizia eu a um amigo". Todos os grifos, que chamam a atenção do leitor para a transformação, são do narrador. 
Alfredo Bosi (2007) faz uma rápida abordagem desse conto, lendo-o a partir de um outro, "Teoria do medalhão", e encontrando em Benedito o medalhão já formado no que seria uma espécie de resultado prático da aplicação do conselho de jamais ter qualquer pensamento próprio dado pelo pai ao filho quando este atinge a maioridade, transmitindo-lhe a mais profunda fórmula para se vencer na vida. A conclusão do crítico é a seguinte: "Evolução é uma apropriação bem-sucedida. O resultado final chama-se posse. Assim na História como na Natureza. O fato de ser uma ideia, uma frase, uma simples metáfora o objeto da apropriação apenas refina o projeto da autoconservação" (BOSI, 2007, p. 119). Como se vê, a leitura de Bosi se concentra no caso individual de Benedito e em sua vitória, interpretada como a concretização de um projeto de autoconservação.

A leitura de Adriana da Costa Teles (2014), no artigo "Benedito e o perfil de um político: uma irônica 'evolução'", leva em conta a de Alfredo Bosi e procura extrapolá-la, localizando na evolução de Benedito algo mais que o caso pessoal. No entanto, é ainda nesse personagem que ela se concentra, uma vez que, depois de uma afirmação de caráter geral segundo a qual "o conto deixa ver vários processos que envolvem mudanças", fecha o foco: "[o] desenrolar de todas essas questões gira em torno de Benedito" (TELES, 2014, p. 200).

Depois de rever minuciosamente a trajetória do personagem, afirma:

A discussão empreendida até aqui mostra justamente que a subtração da fala de Inácio por parte de Benedito é apenas um detalhe em meio a um comportamento maior, que privilegia o empréstimo de ideias alheias na confecção de certa retórica. O fenômeno torna-se ainda mais interessante quando nos atemos a um detalhe que intriga o narrador: Benedito estava convencido de que era ele que havia tido a ideia sobre $o$ Brasil engatinhando. Ou seja, ele parece acreditar que é alguém que tem projetos e ideias boas e promissoras. (TELES, 2014, p. 206)

Para concluir, depois de retomar uma observação geral de Raymundo Faoro sobre como a política tende a ser representada na obra de Machado, a autora diz: "Em certo sentido é o que vemos em 'Evolução'. Um jogo irresponsável governado pela vaidade, cujo fim é a glória pública" (TELES, 2014, p. 207).

Para Adriana Costa Teles, portanto, o conto é um comentário à política brasileira, que apareceria pautada pela vaidade pessoal sinceramente percebida como uma contribuição para a coletividade. Trata-se de leitura 
instigante que, no entanto, deve ser aprofundada, já que há consequências mais abrangentes a serem tiradas acerca do "retrato de Brasil" que o conto esboça.

Isso porque há algo que nem a leitura de Alfredo Bosi nem a de Adriana Costa Teles contemplam: a posição do narrador. Focados em Benedito, percebem as contradições de sua sinceridade sem jamais investigarem a de Inácio. Ora, diferentemente de Benedito, nosso narrador é um homem prático. Ele de fato se envolve em projetos de construção de estrada de ferro. Quando os dois se encontram na Europa, Inácio lá está para viabilizar negócios estrangeiros no Brasil, de tal forma que, no último encontro entre os amigos que o conto narra, Benedito lhe pergunta acerca desses projetos. Eis sua resposta e o diálogo que se segue:

- Dentro de dous anos conto inaugurar o primeiro trecho da estrada.

- E os capitalistas ingleses?

- Que têm?

- Estão contentes, esperançados?

- Muito; não imagina. (ASSIS, 1992, p. 707)

Esse curto diálogo como que ilustra a distância que, sinceramente, Inácio vê separar Benedito de si mesmo. Além de ter a ideia que seria copiada, é ele quem faz o trabalho. Isso já havia sido dito e redito seguidas vezes, o que resulta numa imagem muito alta de si mesmo - alguém que andara pela Europa atrás de dados técnicos e investidores, dizendo "vim cuidar de uma estrada de ferro" (ASSIS, 1992, p. 707) - e muito rebaixada de Benedito - que, estando também por lá, o imita mal, coletando "com muito mais gosto os anexins políticos e fórmulas parlamentares" (ASSIS, 1992, p. 707) do que aquilo que de fato faria a diferença entre ter uma grande ideia e executá-la.

Por outro lado, esse diálogo os aproxima inesperadamente por meio dos capitalistas ingleses. O político iniciante, aliás coerente com a imagem que o narrador cria dele, mostra-se mais preocupado com os capitalistas ingleses do que com os efeitos das estradas de ferro para o progresso nacional. E, com isso, desvela o que Inácio, o narrador, nem de passagem refere, porque talvez o ignore sinceramente: seus interesses pessoais, econômicos, naquela empreitada toda. A indiferença daquele "que tem?" mal encobre a motivação de seus esforços, ou seja, os lucros que a construção de uma obra de grande porte traria a ele. 
E as semelhanças entre Inácio e Benedito - incluída a cegueira sobre si próprios - não se encerram por aí. Antes estão no cerne do conto. Para percebê-las melhor, mais do que indicar a passagem daquele "o senhor dizia" para o "dizia eu", tão enfatizada pelo narrador, é preciso investigar a origem da tal ideia brilhante e de interesse para o país de que Inácio tão acintosamente se apropria.

Inácio e Benedito se conhecem justamente numa viagem de trem. Contato forçado, portanto, que Inácio não deixa de assinalar: "Trocamos algumas palavras, e não tardou conversarmos francamente, ao sabor das circunstâncias que nos impunham a convivência, antes mesmo de saber quem éramos" (ASSIS, 1992, p. 704). Nessa situação, não é de se esperar outra coisa que não a conversa fiada, o papo sobre generalidades. E é assim mesmo que Inácio caracteriza a palestra, com grande ênfase, pela forma como descreve esse primeiro contato:

Naturalmente, o primeiro objeto foi o progresso que nos traziam as estradas de ferro. Benedito lembrava-se do tempo em que toda a jornada era feita às costas de burro. Contamos então algumas anedotas, falamos de alguns nomes, e ficamos de acordo em que as estradas de ferro eram uma condição de progresso do país. Quem nunca viajou não sabe o valor que tem uma dessas banalidades graves e sólidas para dissipar os tédios do caminho. O espírito areja-se, os próprios músculos recebem uma comunicação agradável, o sangue não salta, fica-se em paz com Deus e os homens. (ASSIS, 1992, p. 704)

O tema que primeiro surge é o que a própria situação sugere: as estradas de ferro. Tal tópico é um entre muitos, anedotas, possíveis conhecidos comuns, enfim, banalidades que espantam o tédio que uma viagem, mesmo rapidamente feita, de trem, traz. Há dois elementos nessa descrição que têm grande consequência para o sentido geral do conto.

O primeiro é a admissão, desde o início da narração, de que vincular o progresso do Brasil à construção de estradas de ferro é uma banalidade em si. E, poderíamos acrescentar, não porque seja simplesmente um lugar-comum, mas porque se trata de um disparate. Afinal, não merece outra classificação a ideia de que um país escravocrata, pobre, só poderá superar seus problemas com a modernização dos seus meios de transporte, ou seja lá do que for, sem a reformulação de suas bases sociais - disparate, aliás, que marca a problemática modernização brasileira, que se mostrou repetidamente incapaz de diminuir as enormes distâncias sociais que nos constituem, 
contribuindo mais para aprofundar a disjunção social do que para extinguila, no mesmo passo em que foi criando uma rede de estradas de ferro e, mais tarde, uma indústria automobilística que tornou imprevistamente obsoleta essa mesma rede ferroviária - para nem falar de tantas outras marcas de modernização. É evidente que Inácio não vê o disparate, pronto que está para transformar uma ideia banal num grande achado seu, merecedor de ser roubado por Benedito.

O segundo elemento é ainda mais perturbador e se revela na maneira como a ideia surge nessa conversação, marcando sua verdadeira autoria: "ficamos de acordo em que as estradas de ferro eram uma condição de progresso do país". Como se vê, a evolução vem de antes, ela não começara no "dizia o senhor", mas sim no "ficamos de acordo". Dizendo de outra maneira, essa percepção muda o esquema que Alfredo Bosi descreve para o conto quando diz que, se fosse estruturalista, afirmaria que "o sistema desse conto se desloca sobre um eixo pronominal: tu-nós-eu" (BOSI, 2007, p. 118). Tal eixo é o que Inácio enxerga, já que uma parte dele, a inicial, não lhe ocorre, e precisamente a que transforma o todo em nós-tu-nós-eu. Faz parte do projeto do conto o estabelecimento desse eixo e da percepção restrita do narrador sobre ele, vital para que ele se veja e se caracterize como alguém muito diferente - no sentido da superioridade - de Benedito. É que para ele o sistema não se relaciona com a ideia em si, apenas com a formulação retórica envolvendo a criança que engatinha e que virá a andar. Seu orgulho de autor original não o deixa ver nem a banalidade da ideia por trás da fórmula - a despeito de ele mesmo a ter colocado lado a lado com outras banalidades nem o fato de que suas ideias - para não dizer sua ação modernizadora - são tão artificiais quanto as de Benedito e, ademais, partilhadas com ele desde o princípio.

Quando se leva tudo isso em conta, a evolução em falso que o conto desenha é a de Benedito, sim. Mas é também a de Inácio e de toda uma classe que mira um resultado, vá lá, para o país, simplesmente ignorando o que se passa no restante do espectro da sociedade brasileira. Daí nada evoluir, nem no sentido que Spencer, diretamente evocado, dá à palavra "evolução", nem em seu uso corrente. Tudo permanece igual, mesmo quando tudo muda; tudo é tão semelhante, mesmo quando se apresenta como tão diferente. Como estradas de ferro construídas conjuntamente por escravos, homens livres pobres e imigrantes (LAMOUNIER, 2012), como Inácio e Benedito. Afinal, se, para Inácio, Benedito se apossou de sua ideia, sua vingança é a própria narrativa, que instaura a autoria pessoal numa ideia concebida em conjunto. 
Lido assim, "Evolução" articula de maneira sutil, mas clara, a disjunção brasileira. Não porque trate diretamente dela. Afinal, ele tira sua matéria disjuntiva exatamente do isolamento de perspectiva de uma dada classe. Nem, por outro lado, porque seja formalmente disjuntivo: não há desníveis no conto. O que ocorre é que a narrativa aloja essa disjunção nos desvãos da forma, no intervalo entre a autoridade suposta do narrador e sua limitação de visão. Indica talvez que esta pode ser uma forma viável de encaminhar sob outro enfoque a reflexão acerca da literatura brasileira.

\section{Referências}

ASSIS, Machado de. Evolução. In: Obra completa. Rio de Janeiro: Nova Aguilar, 1992.v. 2.

BOSI, Alfredo. A máscara e a fenda. In: . Machado de Assis: o enigma do olhar.

2. ed. São Paulo: WM Martins Fontes, 2007.

BUARQUE, Chico. As caravanas. In: . Caravanas (encarte do CD). Rio de Janeiro: Biscoito Fino, 2017.

CANDIDO, Antonio. Formação da literatura brasileira. 6. ed. Belo Horizonte: Itatiaia, 1981. v. 1.

LAMOUNIER, Maria Lucia. Ferrovias e mercado de trabalho no Brasil do século XIX. São Paulo: Edusp, 2012.

MACEDO, Joaquim Manuel de. A moreninha - A luneta mágica. São Paulo: Editora Três, 1972.

TELES, Adriana da Costa. Benedito e o perfil de um político: uma irônica "evolução". Machado de Assis em Linha - Revista Eletrônica de Estudos Machadianos, São Paulo, v. 7, n. 14, p. 198-208, dez. 2014. Disponível em: <http://www.scielo.br/pdf/mael/v7n14/1983-6821-mael-7-14-00198.pdf>. Acesso em: 02.06.2019. doi:10.1590/19836821201421214.

LUÍS BUENO é doutor em Teoria e História Literária pela Unicamp (2001) e professor de Literatura Brasileira e Teoria da Literatura na Universidade Federal do Paraná desde 1996. Publicou, além de artigos, alguns livros, entre os quais se contam Uma história do romance de 30 (Edusp/Unicamp, 2006, 2 ed. 2015), A tradição literária brasileira entre a periferia e o centro, organizado em colaboração com Germana Salles e Valéria Augusti (Argos, 2013), Capas de Santa Rosa (Ateliê/SESC, 2016), O hábito da perfeição poemas de Gerard Manley Hopkins (Jabuticaba, 2018) e o romance Paradeiro (Ateliê, 2018). (D) http://orcid.org/0000-0002-50625653. E-mail: luis@ufpr.br

Recebido: 03.06.2019

Aprovado: 28.08.2019 